\title{
Trehalose as an osmolyte in Candidatus Accumulibacter phosphatis
}

\author{
Danny R. de Graaff ${ }^{1}$ (D) - Mark C. M. van Loosdrecht ${ }^{1}$ (D) - Mario Pronk ${ }^{1,2}$ (D)
}

Received: 7 July 2020 / Revised: 30 September 2020 / Accepted: 4 October 2020 / Published online: 19 October 2020

(C) The Author(s) 2020

\begin{abstract}
Candidatus Accumulibacter phosphatis is an important microorganism for enhanced biological phosphorus removal (EBPR). In a previous study, we found a remarkable flexibility regarding salinity, since this same microorganism could thrive in both freshwater- and seawater-based environments, but the mechanism for the tolerance to saline conditions remained unknown. Here, we identified and described the role of trehalose as an osmolyte in $\mathrm{Ca}$. Accumulibacter phosphatis. A freshwater-adapted culture was exposed to a single batch cycle of hyperosmotic and hypo-osmotic shock, which led to the release of trehalose up to $5.34 \mathrm{mg}$ trehalose/g volatile suspended solids (VSS). Long-term adaptation to $30 \%$ seawater-based medium in a sequencing batch reactor (SBR) gave a stable operation with complete anaerobic uptake of acetate and propionate along with phosphate release of $0.73 \mathrm{Pmol} / \mathrm{Cmol}$, and complete aerobic uptake of phosphate. Microbial analysis showed $\mathrm{Ca}$. Accumulibacter phosphatis clade I as the dominant organism in both the freshwater- and seawater-adapted cultures ( $>90 \%$ presence). Exposure of the seawater-adapted culture to a single batch cycle of hyperosmotic incubation and hypo-osmotic shock led to an increase in trehalose release upon hypo-osmotic shock when higher salinity is used for the hyperosmotic incubation. Maximum trehalose release upon hypo-osmotic shock was achieved after hyperosmotic incubation with $3 \times$ salinity increase relative to the salinity in the SBR adaptation reactor, resulting in the release of $11.9 \mathrm{mg}$ trehalose/g VSS. Genome analysis shows the possibility of $\mathrm{Ca}$. Accumulibacter phosphatis to convert glycogen into trehalose by the presence of tre $X$, tre $Y$, and tre $Z$ genes. Addition of trehalose to the reactor led to its consumption, both during anaerobic and aerobic phases. These results indicate the flexibility of the metabolism of $\mathrm{Ca}$. Accumulibacter phosphatis towards variations in salinity.
\end{abstract}

\section{Key points}

- Trehalose is identified as an osmolyte in Candidatus Accumulibacter phosphatis.

- Ca. Accumulibacter phosphatis can convert glycogen into trehalose.

- Ca. Accumulibacter phosphatis clade I is present and active in both seawater and freshwater.

Keywords Accumulibacter $\cdot$ Trehalose $\cdot$ Phosphate $\cdot$ Seawater $\cdot$ Salinity $\cdot$ EBPR

\section{Introduction}

Enhanced biological phosphorus removal (EBPR) is an important technology for the removal of phosphate from

Electronic supplementary material The online version of this article (https://doi.org/10.1007/s00253-020-10947-8) contains supplementary material, which is available to authorized users.

Mario Pronk

M.Pronk@tudelft.nl

1 Department of Biotechnology, Delft University of Technology, van der Maasweg 9, 2629 HZ Delft, The Netherlands

2 Royal HaskoningDHV, Laan1914 35, 3800

AL Amersfoort, The Netherlands wastewater streams (Blackall et al. 2002; Seviour et al. 2003; Singh and Srivastava 2011). Anaerobic uptake of volatile fatty acids (VFA) and aerobic uptake of phosphate by phosphate-accumulating organisms (PAO) lead to the complete removal of both chemical oxygen demand (COD) and phosphate in one process step (Comeau et al. 1986; Smolders et al. 1994). This process has been extensively studied under freshwater conditions. Saline process conditions have also been investigated, and recently, it has been shown that also seawater-based influents can lead to good EBPR efficiency (Wang et al. 2009; Guo et al. 2018; De Graaff et al. 2020). Most interestingly, short-term exposure of this seawateradapted culture to freshwater led to the release of COD, which was proposed to be related to osmolyte excretion. 
Intracellular accumulation of osmolytes is a common mechanism for halophilic organisms to survive in saline environments (da Costa et al. 1998; Roeßler and Müller 2001). Osmolytes, sometimes also called compatible solutes or osmoprotectants, are small organic molecules that can be either zwitterionic, noncharged, or anionic, which are used to balance internal and external osmotic pressure without interfering with cellular processes (Sleator and Hill 2001; Roberts 2005). There is a large range of osmolytes that are widely conserved among organisms ranging from plants to bacteria and fungi (Yancey et al. 1982; Csonka 1989; Klipp et al. 2005). Production of osmolytes can be induced by an increase in external osmotic pressure, and release is triggered by a decrease in osmotic pressure (Guillouet and Engasser 1995; Kempf and Bremer 1998; Sauer and Galinski 1998).

This behavior signifies the importance of understanding osmolyte metabolism in wastewater systems that might undergo dynamic changes in salt content of the influent, as can occur due to industrial discharges or seawater intrusion in the sewer system. The role of osmolytes in saline wastewater treatment has regularly been reported for nitrifying sludge and methanogenic sludge (Corsino et al. 2016; Wang et al. 2017; Vyrides and Stuckey 2017; Sudmalis et al. 2018). The most detailed salinity effect described for Candidatus Accumulibacter phosphatis is an increase in maintenance coefficients after adaptation to $\mathrm{NaCl}$-based influent (Welles et al. 2014). Identification and production of osmolytes or their function within $\mathrm{Ca}$. Accumulibacter phosphatis under saline conditions have not been described in literature.

In this paper, we identified and described the role of trehalose as an osmolyte in a $\mathrm{Ca}$. Accumulibacter phosphatis enrichment culture. A freshwater-adapted enrichment culture was adapted to a salinity level of $30 \%$ seawater. The impact on EBPR efficiency and microbial community composition was analyzed. The enrichment cultures were exposed to hyperosmotic incubation followed by hypo-osmotic shock, to study the effect on trehalose production and release. The aerobic and anaerobic uptake of trehalose was studied. The link between glycogen storage pool and trehalose metabolism and the impact of this so-far unknown carbon pool on the EBPR processes are discussed.

\section{Materials and methods}

\section{Reactor operation}

A freshwater-adapted $\mathrm{Ca}$. Accumulibacter phosphatis enrichment reactor was operated as described in Guedes da Silva et al. (2018). This reactor was subsequently adapted to a salinity level of $30 \%$ seawater with the following operational parameters.
A 1.5-L stirred tank reactor was operated as a sequencing batch reactor (SBR) with a 6-h cycle. Each cycle consisted of 20 min settling, 15 min effluent withdrawal, $5 \mathrm{~min} \mathrm{~N}_{2}$ sparging, 5 min feeding, $135 \mathrm{~min}$ anaerobic phase, and $180 \mathrm{~min}$ aerobic phase. The sludge retention time (SRT) was maintained at 10 days through a short cyclical effluent removal during the mixed aerobic phase. The hydraulic retention time (HRT) was equal to $12 \mathrm{~h}$ (50\% exchange ratio). $\mathrm{pH}$ was controlled at $7.0 \pm$ 0.1 by dosing either $0.4 \mathrm{M} \mathrm{HCl}$ or $0.4 \mathrm{M} \mathrm{NaOH}$. Temperature was controlled at $20 \pm 1^{\circ} \mathrm{C}$. Conductivity in the bulk liquid was used to follow phosphate release and uptake profiles as described in Kim et al. (2007). The on-line profiles were used to verify steady operation of the reactor.

The feed of $750 \mathrm{~mL}$ was combined from two separate media: a concentrated COD medium and a concentrated mineral medium, which were both diluted with artificial seawater (final concentration of $10 \mathrm{~g} / \mathrm{L}$ Instant Ocean ${ }^{\circledR}$ sea salts) prior to feeding into the reactor. The combination of these solutions led to influent concentrations of $400 \mathrm{mg} \mathrm{COD} / \mathrm{L}(260 \mathrm{mg}$ $\mathrm{COD} / \mathrm{L}$ from $\mathrm{NaAc} \cdot 3 \mathrm{H}_{2} \mathrm{O}$ and $140 \mathrm{mg} \mathrm{COD} / \mathrm{L}$ from $\mathrm{NaPr}$ ), $50 \mathrm{mg} \mathrm{PO}{ }_{4}^{3-}-\mathrm{P} / \mathrm{L}$ (from $222 \mathrm{mg} / \mathrm{L} \mathrm{NaH}_{2} \mathrm{PO}_{4} \cdot 3 \mathrm{H}_{2} \mathrm{O}$ ), $40 \mathrm{mg}$ $\mathrm{NH}_{4}{ }^{+}-\mathrm{N} / \mathrm{L}$ (from $152.5 \mathrm{mg} / \mathrm{L} \mathrm{NH}{ }_{4} \mathrm{Cl}$ ), $158.6 \mathrm{mg} / \mathrm{L} \mathrm{MgSO}_{4}$. $7 \mathrm{H}_{2} \mathrm{O}, 48 \mathrm{mg} / \mathrm{L} \mathrm{KCl}, 40 \mathrm{mg} / \mathrm{L} \mathrm{CaCl}{ }_{2} \cdot 2 \mathrm{H}_{2} \mathrm{O}, 4 \mathrm{mg} / \mathrm{L} \mathrm{N}-$ allylthiourea, $4 \mathrm{mg} / \mathrm{L}$ yeast extract, and $0.6 \mathrm{~mL} / \mathrm{L}$ trace element solution (Vishniac and Santer 1957).

Trehalose uptake experiments in the reactor were performed by addition of a stock solution $(5 \mathrm{~mL})$ of trehalose that was prepared in artificial seawater $(10 \mathrm{~g} / \mathrm{L}$ Instant Ocean $\circledast$ sea salts, similar to the reactor concentration). This solution was manually added to the reactor at either the start of aeration or the start of the anaerobic phase. The final concentration of trehalose in the reactor was $100 \mathrm{mg} / \mathrm{L}$. When this trehalose solution was added at the start of the anaerobic phase, acetate and propionate were not added to the reactor.

\section{Batch tests}

Sludge was taken from the reactor at the end of the aerobic reactor cycle, and transferred to flasks with $100 \mathrm{~mL}$ working volume. These flasks contained either demineralized water (buffered at $\mathrm{pH} 7.0 \pm 0.1$ with $4.0 \mathrm{mM}$ HEPES buffer) or a solution of Instant Ocean ${ }^{\circledR}$ sea salts, and were sparged with nitrogen gas prior to adding the sludge. Samples were taken over time and filtered through a $0.45-\mu \mathrm{m}$ PVDF filter. After the anaerobic phase, the sludge was allowed to settle in the flask, and liquid was decanted and replaced by $100 \mathrm{~mL}$ demineralized water, and aerated for a duration of $60 \mathrm{~min}$. No nutrients were added to the liquid during these batch tests.

The respective masses of all samples were registered to compensate for mass decrease during calculations. The amount of biomass was determined by filtering the granules at the end of the test, washing with demineralized water to 
remove salts, drying for $24 \mathrm{~h}$ at $105^{\circ} \mathrm{C}$, and burning for $2 \mathrm{~h}$ at $550^{\circ} \mathrm{C}$. All tests were done in duplicate.

\section{Analytical methods}

Concentrations of phosphate were measured on a Thermo Fisher Gallery Discrete Analyzer (Thermo Fisher Scientific, Waltham, USA). Acetate and propionate were measured by HPLC with an Aminex HPX-87H column from Biorad, coupled to an RI and UV detector, using $0.01 \mathrm{M}$ phosphoric acid as eluent. Trehalose analysis was performed with a Dionex ICS- $5000^{+}$(Thermo Fisher Scientific, USA), a CarboPac PA20 3*150 mm column, and an Amino Trap $3 * 30 \mathrm{~mm}$ pre-column (column temperature $30^{\circ} \mathrm{C}$ ). Injection volume was $2-10 \mu \mathrm{L}$. Eluents used were ultrapure water, $200 \mathrm{mM} \mathrm{NaOH}$, and $50 \mathrm{mM}$ sodium acetate with $200 \mathrm{mM}$ $\mathrm{NaOH}$. Flow equaled $0.5 \mathrm{~mL} / \mathrm{min}$, isocratic with $10 \mathrm{mM}$ $\mathrm{NaOH}$ during 20 min, followed by a cleaning step with $200 \mathrm{mM} \mathrm{NaOH}$ for $20 \mathrm{~min}$ and sodium acetate for $60 \mathrm{~min}$ in total. Samples were analyzed pulsed amperometrically with a quadruple wave form, with gold electrode and $\mathrm{Ag} / \mathrm{AgCl}$ reference electrode.

\section{Fluorescence in situ hybridization}

The handling, fixation, and staining of fluorescence in situ hybridization (FISH) samples were performed as described in Bassin et al. (2011). A mixture of PAO462, PAO651, and PAO846 probes (PAOmix) was used for visualizing polyphosphate-accumulating organisms (PAO) (Crocetti et al. 2000). A mixture of GAOQ431 and GAOQ989 probes (GAOmix) was used for visualizing glycogen-accumulating organisms (GAO) (Crocetti et al. 2002). A mixture of EUB338, EUB338-II, and EUB338-III probes was used for staining all bacteria (Amann et al. 1990; Daims et al. 1999). Ca. Accumulibacter clade I was visualized by Acc-I-444, and $\mathrm{Ca}$. Accumulibacter clade II was visualized by Acc-II-444 (Flowers et al. 2009). Images were taken with a Zeiss Axioplan 2 epifluorescence microscope equipped with filter set 26 (bp 575e625/FT645/bp 660e710), 20 (bp 546/12/FT560/bp 575e640), and 17 (bp 485/20/FT 510/bp 5515e565) for Cy5, $\mathrm{Cy} 3$, and fluos, respectively.

The biovolume of PAO was calculated by counting the amounts of colored pixels from the FISH images, calculated with simple in-house software: The amount of pixels that were colored with the EUB338 probe (staining all eubacteria) was used as $100 \%$, and the amount of pixels that were colored with the PAOmix probes (PAO462, PAO651, and PAO846 probes) was used for calculation of their respective fraction. A total of 10 representative pictures were used for calculation of the PAO fraction.

\section{Amplicon sequencing}

DNA was extracted using the DNeasy UltraClean Microbial Kit (Qiagen, The Netherlands). Approximately $250 \mathrm{mg}$ wet biomass was treated according to the standard protocol except an alternative lysis was implemented. This included a combination of $5 \mathrm{~min}$ of heat $\left(65^{\circ} \mathrm{C}\right)$ followed by $5 \mathrm{~min}$ of beadbeating for cell disruption on a Mini-Beadbeater-24 (Biospec, USA). After extraction, the DNA was checked for quality by gel electrophoresis and quantified using a Qubit 4 (Thermo Fisher Scientific, USA).

After quality control, samples were sent to Novogene Ltd. (Hong Kong, China) for Amplicon sequencing of the V3-4 region of the 16S-rRNA gene (position 341-806) on an Illumina paired-end platform. After sequencing, the raw reads were quality filtered, chimeric sequences were removed, and operational taxonomic units (OTUs) were generated on the base of $\geq 97 \%$ identity. Subsequently, microbial community analysis was performed by Novogene using Mothur \& Qiime software (V1.7.0). For phylogenetical determination, a most recent SSURef database from SILVA (http://www.arb-silva.de/) was used.

\section{Genome analysis}

Fifty-nine available metagenome sequences of Candidatus Accumulibacter phosphatis enrichment cultures were obtained from JGI IMG database. These metagenomes were compared with protein sequences of TreX, TreY, and TreZ proteins, obtained from the NCBI protein database. BLASTp was performed using the on-line BLASTp tool by JGI IMG. Alignment was performed according to the algorithm as described in Altschul et al. (1997) and Schäffer et al. (2001). Lower $E$-values indicate a lower uncertainty in the presence of certain sequences. Values lower than $1 \mathrm{E}-40$ were set as threshold for positive results.

\section{Results}

\section{Trehalose release from freshwater-adapted $\mathrm{Ca}$. Accumulibacter phosphatis enrichment culture}

The freshwater-adapted enrichment culture of $C a$. Accumulibacter phosphatis was operated as described in Guedes da Silva et al. (2018). This reactor had a $C a$. Accumulibacter phosphatis fraction of $>90 \%$ of the biovolume as determined by fluorescence in situ hybridization (FISH) analysis. No trehalose was measured in the reactor during a normal cycle of anaerobic COD uptake and phosphate release, and aerobic phosphate uptake.

This freshwater-adapted sludge was used in a batch test to assess the potential for intracellular trehalose production. A sludge sample was anaerobically incubated in $10 \mathrm{~g} / \mathrm{L}$ artificial seawater ( $30 \%$ of seawater) for $60 \mathrm{~min}$ without the presence of 
a COD source. Afterwards, the sludge was transferred to aerated demineralized water for another $60 \mathrm{~min}$. No nutrients were added to assess the effect of only the salinity increase. A control sample was tested in the same way, but with anaerobic incubation in demineralized water instead of artificial seawater. Trehalose concentrations were measured in the liquid phase over time (Fig. 1). The anaerobic incubation of freshwater-adapted $\mathrm{Ca}$. Accumulibacter phosphatis for $60 \mathrm{~min}$ in $10 \mathrm{~g} / \mathrm{L}$ artificial seawater and subsequent transfer to a freshwater medium resulted in the release of $5.34 \mathrm{mg}$ trehalose/g volatile suspended solids (VSS) within only 10 min after the osmotic downshock. The control experiment with anaerobic incubation in demineralized water yielded negligible release of trehalose after osmotic downshock.

These results signify the potential for freshwater-adapted $\mathrm{Ca}$. Accumulibacter phosphatis sludge to adapt to a short-term sudden increase in salinity by producing trehalose. The next question is whether this enrichment culture can adapt to prolonged exposure to increased seawater salinity and how this influences trehalose production.

\section{Long-term adaptation of $\mathrm{Ca}$. Accumulibacter phosphatis to seawater}

A $\mathrm{Ca}$. Accumulibacter phosphatis enrichment reactor was operated with $30 \%$ seawater $(10 \mathrm{~g} / \mathrm{L}$ total dissolved salts). Acetate and propionate were added anaerobically and completely consumed within $30 \mathrm{~min}$ after feeding. Phosphate was released up to $167 \mathrm{mg} \mathrm{PO}_{4}{ }^{3-}-\mathrm{P} / \mathrm{L}(0.73 \mathrm{Pmol} / \mathrm{Cmol})$, and completely taken up during aeration. Stable on-line measurements of $\mathrm{pO}_{2}, \mathrm{pH}$, and

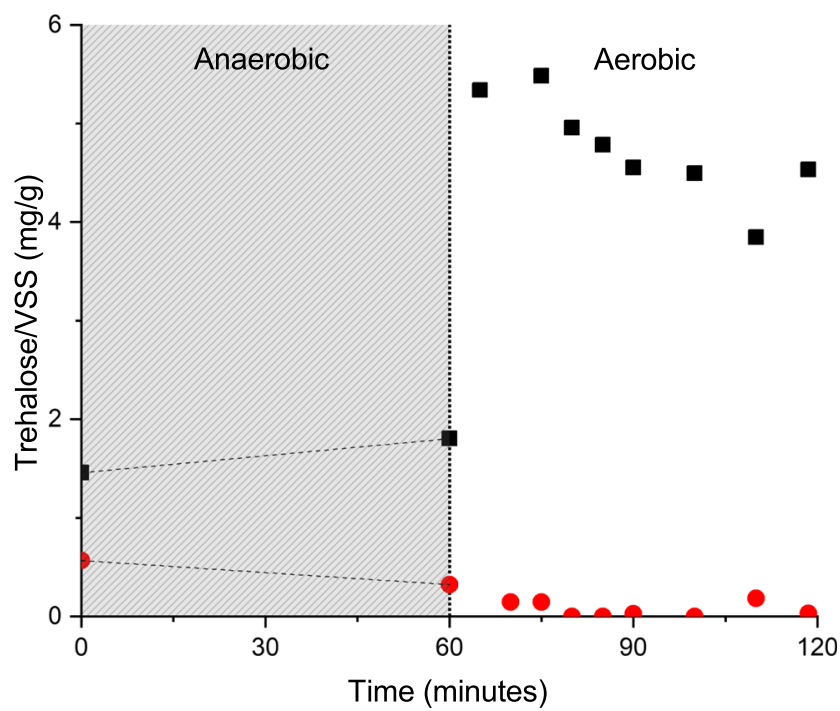

Fig. 1 Trehalose release of freshwater-adapted $\mathrm{Ca}$. Accumulibacter phosphatis enrichment culture after 60 min anaerobic incubation in either $30 \%$ seawater (black squares) or demineralized water (red circles), followed by exposure to aerated demineralized water. The gray area denotes the anaerobic period, and the white area notes the aerobic period conductivity confirmed the occurrence of a pseudo steady state during 126 days of stable operation.

\section{Microbial community analysis}

The microbial community of the seawater-adapted culture was analyzed by means of fluorescence in situ hybridization (FISH) and next-generation amplicon sequencing (NGS). FISH analysis with PAO-specific probes and GAO-specific probes showed abundance of PAO and complete absence of GAO (Fig. 2a). The biovolume of the $30 \%$ seawater-adapted PAO community as deduced from the FISH microscopy was $>90 \%$. Clade differentiation by means of $\mathrm{Ca}$. Accumulibacter clade I- and clade II-specific probes showed the presence of clade I, while clade II was not observed (Fig. 2b, c). The typical morphology of $\mathrm{Ca}$. Accumulibacter clade I was verified with brightfield microscopy imaging (Fig. 2d).

NGS analysis showed only a $33 \%$ relative abundance of $\mathrm{Ca}$. Accumulibacter (Fig. 3). The relative OTU count of $\mathrm{Ca}$. Accumulibacter is much lower than the fraction that was observed with FISH microscopy, which could be due to bias in extraction and quantification of PAO cultures (StokholmBjerregaard et al. 2017).

\section{Trehalose release from seawater-adapted $\mathrm{Ca}$. Accumulibacter phosphatis sludge}

A single cycle of hyperosmotic incubation and hypo-osmotic shock in a freshwater-adapted $\mathrm{Ca}$. Accumulibacter phosphatis enrichment culture caused the release of $5.34 \mathrm{mg}$ trehalose $/ \mathrm{g}$ VSS (Fig. 1). This led to the question whether seawateradapted $\mathrm{Ca}$. Accumulibacter phosphatis will release more trehalose, and whether exposure to even higher osmotic pressures will also lead to more intracellular trehalose production. Therefore, the seawater-adapted enrichment culture was anaerobically incubated in different concentrations of salinity (hyperosmotic incubation). Subsequently, they were exposed to demineralized water in order to release their produced trehalose (hypo-osmotic shock), similar to the experiment in Fig. 1. Trehalose was measured in the liquid phase during the aerated downshock (Fig. 4).

The control sample of $30 \%$ seawater ( $1 \times$ relative salinity) led to the release of $1.0 \mathrm{mg}$ trehalose/g VSS after hypoosmotic shock in demineralized water, within 5 min of the hypo-osmotic shock. This amount increased to $9.2 \mathrm{mg}$ trehalose/g VSS and $11.9 \mathrm{mg}$ trehalose/g VSS after anaerobic incubation in $2 \times$ and $3 \times$ relative salinity, respectively. After anaerobic incubation in four times relative salinity, the amount of released trehalose decreased to $4.9 \mathrm{mg}$ trehalose/g VSS. Negligible amounts of trehalose uptake over time were measured during $60 \mathrm{~min}$ of aeration. The amount of phosphate release was similar in all samples (between 8.4 and $9.1 \mathrm{mg} / \mathrm{L}$ within 10 min of hypo-osmotic shock). 
Fig. 2 Fluorescence in situ hybridization (FISH) analysis of $30 \%$ seawater-adapted $\mathrm{Ca}$. Accumulibacter phosphatis enrichment culture, with PAOmix (cy3, red; a), GAOmix (fluos, green), EUB338 (cy5, blue); b, c), Ca. Accumulibacter clade I (cy3, red), $\mathrm{Ca}$. Accumulibacter clade II (fluos, green), EUB338 (cy5, blue); $\mathbf{d}$ brightfield microscopy image showing $\mathrm{Ca}$.

Accumulibacter clade I morphology. Scale bar equals a $20 \mu \mathrm{m}$ or b $100 \mu \mathrm{m}$
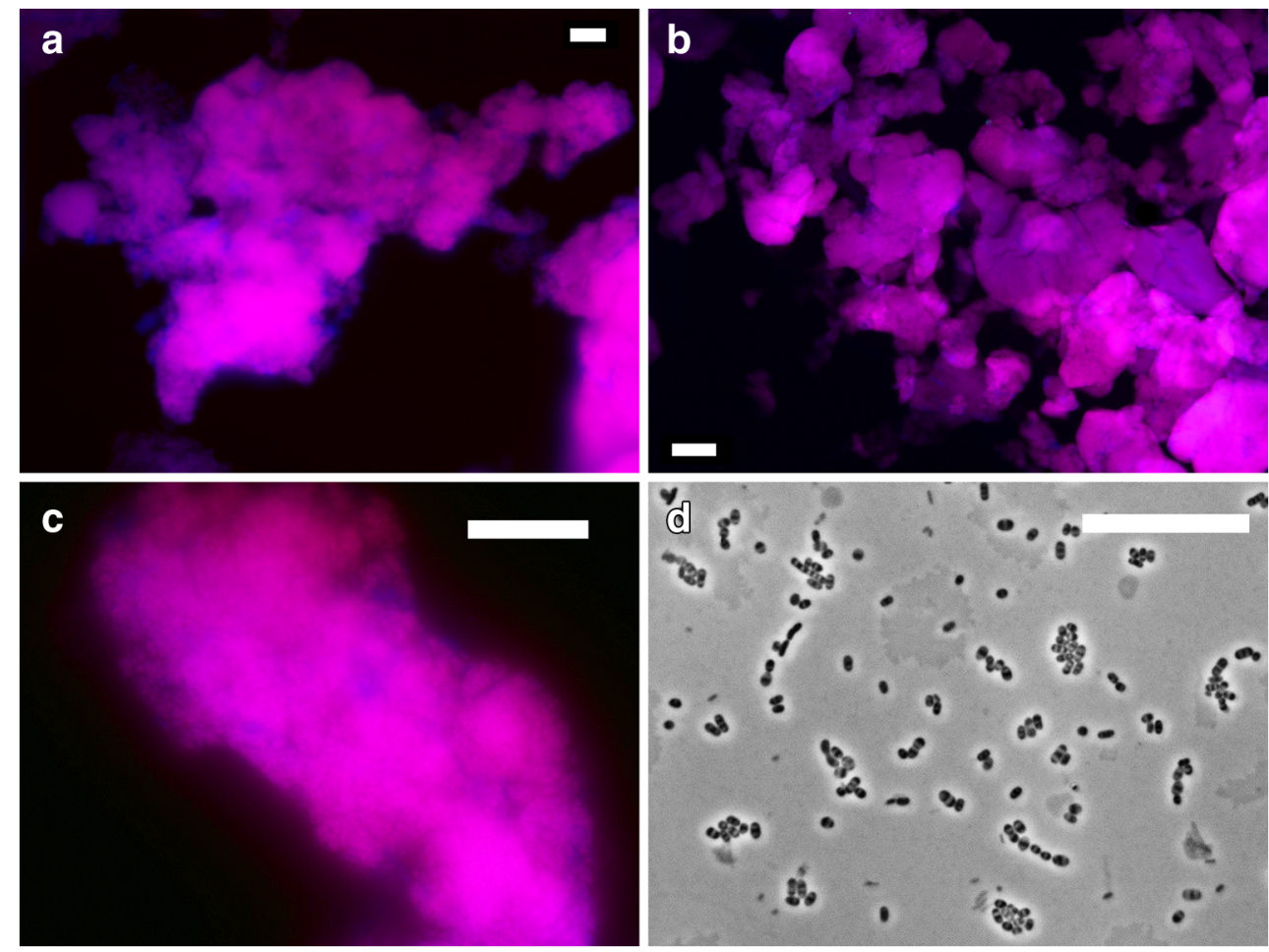

Trehalose uptake by seawater-adapted $\mathrm{Ca}$. Accumulibacter phosphatis enrichment culture

Our previous results showed the capacity of intracellular trehalose production, but uptake of external trehalose can give great insight into a potential new carbon source for culturing $\mathrm{Ca}$. Accumulibacter phosphatis. Therefore, trehalose was added to the reactor during both aeration (Fig. 5) and anaerobic feeding, replacing acetate and propionate as the COD source (Fig. 6). Characteristic values are shown in Table 1.

Trehalose was taken up both aerobically and anaerobically. After aerobic addition, phosphorus uptake continued with a

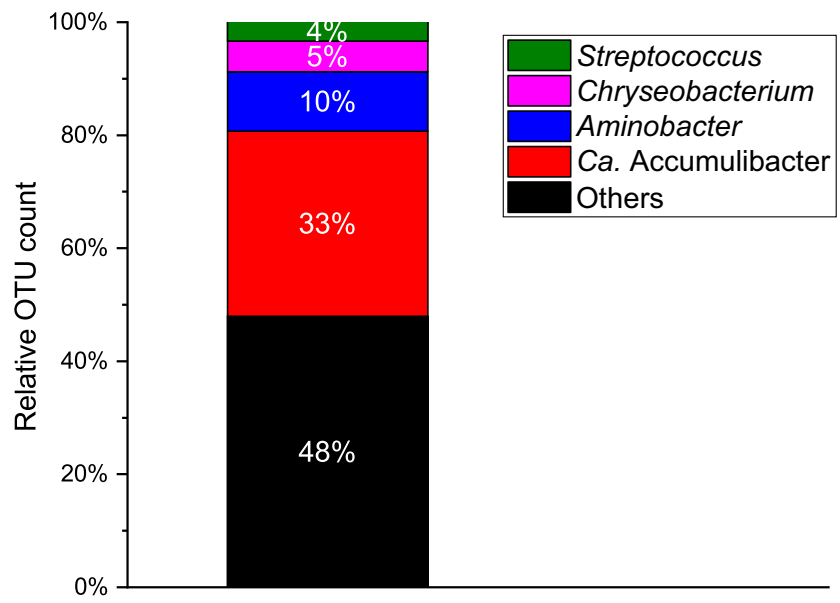

Fig. 3 Relative OTU count of the most abundant genera of a $30 \%$ seawater-adapted $\mathrm{Ca}$. Accumulibacter phosphatis enrichment culture similar rate compared to the regular phosphorus uptake rate (without the presence of any trehalose). Not all trehalose was taken up aerobically, so it leaked into the subsequent anaerobic cycle during which fresh VFA (acetate and propionate) were added to the reactor sludge. The presence of trehalose did not interfere with VFA uptake, but the secondary phosphorus release rate after VFA uptake increased from 6.3 to $9.3 \mathrm{mg} \mathrm{P} / \mathrm{g} \mathrm{VSS} / \mathrm{h}$. Complete replacement of VFA by

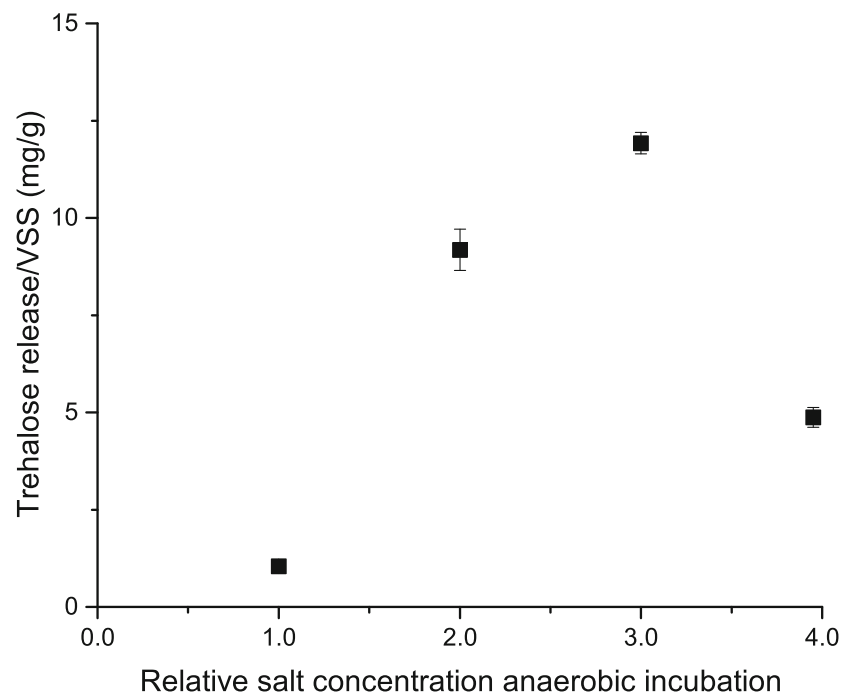

Fig. 4 Concentrations of released trehalose by the $30 \%$ seawater-adapted $\mathrm{Ca}$. Accumulibacter phosphatis enrichment culture, during aerated downshock in demineralized water, after $60 \mathrm{~min}$ anaerobic incubation in either $1 \times, 2 \times, 3 \times$, or $4 \times$ relative salt concentration compared to $30 \%$ seawater 
Fig. 5 Aerobic addition of trehalose in the $30 \%$ seawateradapted $\mathrm{Ca}$. Accumulibacter phosphatis enrichment reactor. Concentrations of phosphate (black squares), acetate (red circles), propionate (green triangles), and trehalose (blue diamonds) are measured over time. The gray areas denote the anaerobic periods, and the white area denotes the aerobic period

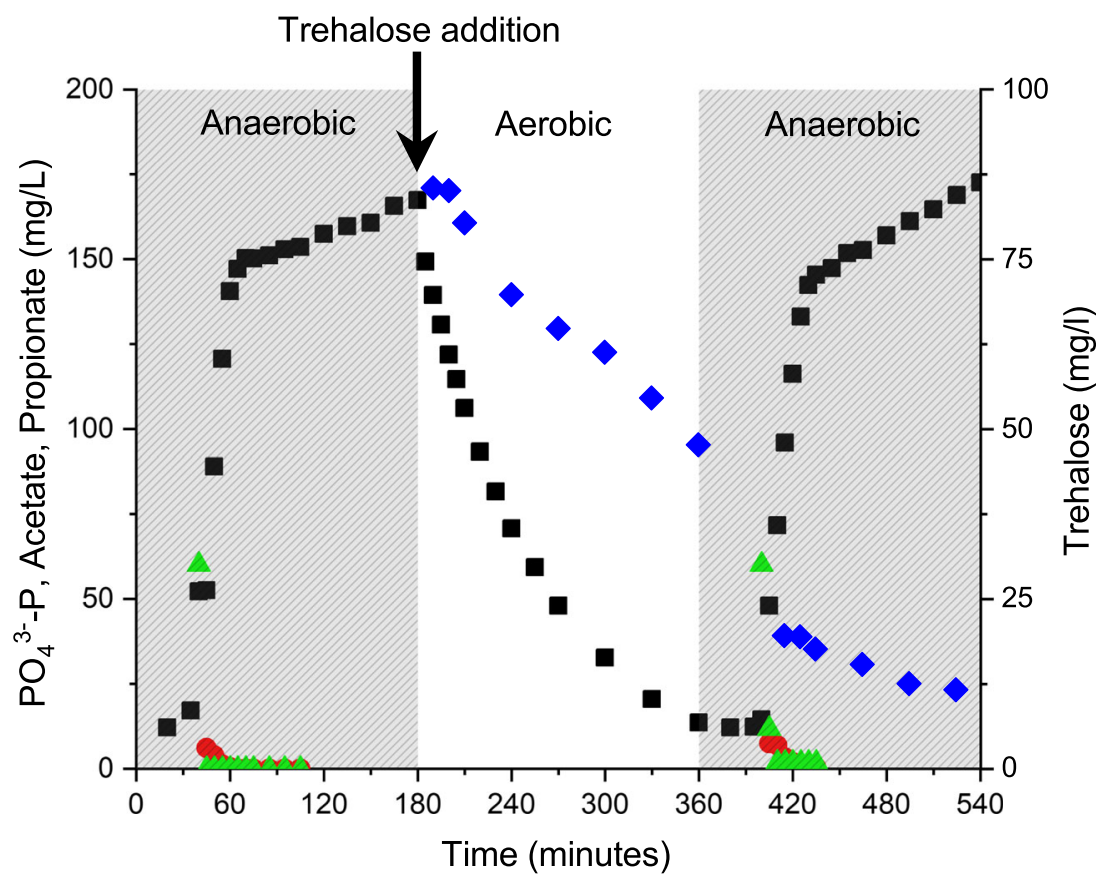

trehalose in the anaerobic influent gave a similar phosphorus release rate of $9.5 \mathrm{mg} \mathrm{P} / \mathrm{g} \mathrm{VSS} / \mathrm{h}$. The aerobic phosphorus uptake rate decreased by $65 \%$ compared to the regular reactor cycle with anaerobic VFA consumption.

\section{Metabolic pathway analysis for trehalose production and uptake in $\mathrm{Ca}$. Accumulibacter phosphatis}

An increase in osmotic pressure led to an increase in trehalose production (Fig. 1, Fig. 4). This raises the question through which metabolic pathway this production occurs. Conversion of glycogen into trehalose is a commonly described pathway (Elbein et al. 2003; Pade et al. 2014). The presence of glycogen pools in $\mathrm{Ca}$. Accumulibacter phosphatis makes this pathway a suitable candidate for analysis.

Conversion of glycogen into trehalose commonly occurs in a two-step TreYZ pathway (Maruta et al. 1996; Ruhal et al. 2013). TreY converts the $\alpha-1,4$ bonds in glycogen into $\alpha-1,1$ bonds, from which trehalose disaccharides are cleaved by TreZ. This set of reactions can be aided by the presence of
Fig. 6 Anaerobic addition of trehalose by replacement of acetate and propionate during feeding in the $30 \%$ seawateradapted $\mathrm{Ca}$. Accumulibacter phosphatis enrichment reactor. Concentrations of phosphate (black squares) and trehalose (blue diamonds) are measured over time. The gray-out area denotes the anaerobic period, and the white area notes the aerobic period

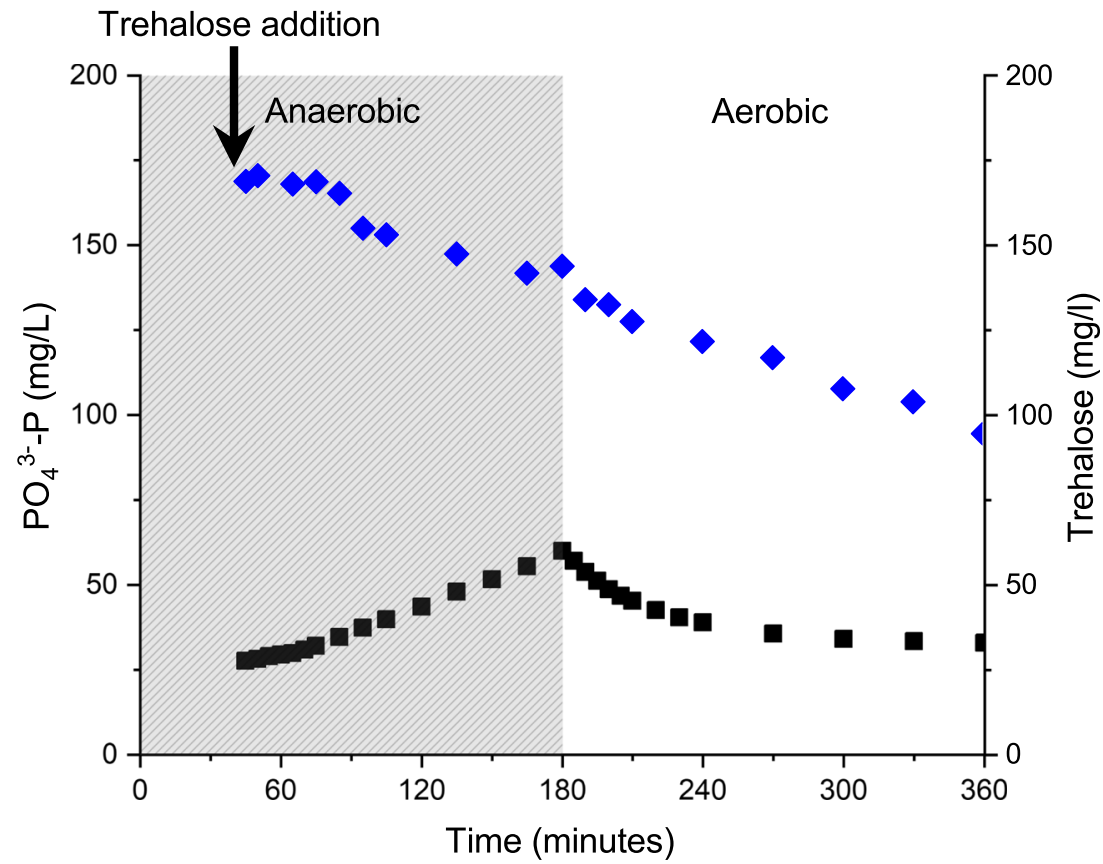


Table 1 Characteristic values of the $30 \%$ seawater-adapted $\mathrm{Ca}$. Accumulibacter phosphatis enrichment culture after addition of trehalose to the enrichment reactor

\begin{tabular}{|c|c|c|c|c|c|}
\hline & Regular cycle & $\begin{array}{l}\text { Aerobic trehalose } \\
\text { addition }\end{array}$ & $\begin{array}{l}\text { Subsequent } \\
\text { anaerobic cycle }\end{array}$ & $\begin{array}{l}\text { Anaerobic trehalose } \\
\text { addition }\end{array}$ & $\begin{array}{l}\text { Subsequent } \\
\text { aerobic cycle }\end{array}$ \\
\hline Trehalose present & - & + & + & + & + \\
\hline Acetate + propionate present & + & - & + & - & - \\
\hline Aerobic trehalose uptake rate (mg trehalose/g VSS/h) & & 8.0 & & & 11.2 \\
\hline Anaerobic trehalose uptake rate (mg trehalose/g VSS/h) & & & 2.8 & 9.7 & \\
\hline Maximal aerobic P-uptake rate (mg P/g VSS/h) & 53.3 & 47.8 & & & 18.5 \\
\hline Maximal anaerobic P-release rate (mg P/g VSS/h) & 262.0 & & 208.8 & 9.5 & \\
\hline Anaerobic P-release after COD uptake (mg P/g VSS/h) & 6.3 & & 9.3 & & \\
\hline Net anaerobic phosphate release $\left(\mathrm{mg} \mathrm{PO}_{4}{ }^{3-}-\mathrm{P} / \mathrm{L}\right)$ & 161.2 & & 166.4 & 56.9 & \\
\hline
\end{tabular}

Values are shown for both the aerobic and anaerobic phases during which trehalose was added, and for the subsequent anaerobic or aerobic phase, respectively

TreX, which is capable of debranching glycogen chains (Seibold and Eikmanns 2007).

Uptake of trehalose by bacteria commonly involves breakdown of trehalose into glucose monomers by trehalase (Boos et al. 1990). In Escherichia coli, for example, trehalose is broken down into glucose monomers by periplasmic trehalase, and subsequently taken up by the phosphotransferase system as glucose-6phosphate (Gutierrez et al. 1989). Presence of the treA gene that encodes for trehalase can indicate whether $\mathrm{Ca}$. Accumulibacter phosphatis has a similar mechanism.

A total of $59 \mathrm{Ca}$. Accumulibacter phosphatis metagenomes have been analyzed for the presence of genes that encode for TreY, TreZ, TreX, and TreA (Supplemental Material 1). Protein sequences have been used from other bacterial species, and these have been aligned to the metagenome of $\mathrm{Ca}$. Accumulibacter phosphatis cultures. Lower $E$-values indicate a higher certainty of the gene being present in the genome. All genes that encode for TreY, TreZ, TreX, and TreA have very low $E$-values, close to or equal to zero. This indicates that the probability for conversion of glycogen to trehalose through the TreYZ pathway is highly likely. Uptake of trehalose can similarly occur by hydrolysis of trehalose into glucose monomers.

\section{Discussion}

\section{Trehalose in Candidatus Accumulibacter phosphatis}

This study shows the presence and role of trehalose in $\mathrm{Ca}$. Accumulibacter phosphatis. Excretion of trehalose after a hypo-osmotic shock revealed the presence of intracellular trehalose pools. Both freshwater-adapted and seawater-adapted cultures produce trehalose after a hyperosmotic incubation, which indicates the remarkable flexibility of $C a$. Accumulibacter phosphatis towards salinity variations.
These results signify the importance of trehalose in salt adaptation, and can explain the flexibility of the EBPR process towards increased salinity (De Graaff et al. 2020).

The presence of trehalose is of major importance for accurately describing the metabolism of $\mathrm{Ca}$. Accumulibacter phosphatis. Metabolic models have so far not included the presence of this compound. Quantification of intracellular trehalose pools will be essential for further research. However, common methods for glycogen quantification by extraction and analysis of its hydrolyzed glucose monomers could be interfering, since trehalose is also composed of glucose monomers (Elbein and Mitchell 1973). Previous studies could potentially even have overestimated their glycogen pools, if trehalose would have been present in significant amounts.

\section{Metabolic link between glycogen and trehalose}

A metabolic link between glycogen and trehalose in Candidatus Accumulibacter phosphatis is proposed. This link is similar to Saccharomyces cerevisiae, where glycogen and trehalose have commonly been described in conjunction (François and Parrou 2001). Trehalose can be produced from glycogen through a simple 2-step enzymatic reaction by TreY and TreZ enzymes (Maruta et al. 1996). TreY can convert $\alpha(1-4)$ glucose polymers such as glycogen into maltooligosyl-trehalose, while TreZ can subsequently hydrolyze into trehalose sugars.

Genome analysis shows that treX, tre $Y$, and tre $Z$ genes are present in the genome of $C a$. Accumulibacter phosphatis. The results presented here indicate that trehalose can be produced very rapidly (Fig. 1, Fig. 4), likely enabled by these enzymes. A deeper understanding of the exact regulation of conversion of glycogen into trehalose will lead to improvement of metabolic models. Stoichiometric and kinetic quantification of intracellular metabolite concentrations will be key for filling the gaps in this pathway. 
Excreted trehalose is also taken up again albeit at a relatively low rate. $\mathrm{Ca}$. Accumulibacter phosphatis is described as not using glucose, but trehalose seems to be a sugar substrate that is metabolized by this species. This can occur through hydrolysis of trehalose by a trehalase enzyme and subsequent use of the produced glucose. There is, however, also a direct pathway described for conversion of trehalose into glycogen, but this seems limited to mycobacteria (Chandra et al. 2011).

\section{Optimum in trehalose release after short-term incu- bation in higher salinities}

Hyperosmotic incubation has frequently been described to be a trigger for intracellular osmolyte production (Guillouet and Engasser 1995; Skjerdal et al. 1996; Kempf and Bremer 1998; Morbach and Krämer 2003). The amount of trehalose released after hypo-osmotic shock increased with the salinity level during the preceding anaerobic hyperosmotic incubation. Trehalose release per VSS increased from $2.1 \mathrm{mg}$ trehalose/ g VSS at the adapted level of $30 \%$ seawater, to $12 \mathrm{mg}$ trehalose/g VSS at three times this salinity. Incubation in four times the adapted salinity gives a much lower release of $4.9 \mathrm{mg}$ trehalose/g VSS (Fig. 4).

A common response to hyperosmotic incubation is the downregulation of the metabolic rate in both eukaryotic and prokaryotic cells (Bishop et al. 1994; Dai and Zhu 2018). Shrinking of bacterial cells leads to an increase in metabolite and protein concentrations, also known as molecular crowding (Zimmerman and Minton 1993). This can result in a decrease in diffusion of proteins and a change in occurrence of metabolic reactions (Lang et al. 1998; Ellis and Minton 2003; Dorsaz et al. 2010; Miermont et al. 2013).

Intracellular conversion of glycogen into trehalose can therefore have a lower rate at higher salinity. The 1-h hyperosmotic incubation could have been too short to reach maximal trehalose concentrations. Longer-term salt adaptation would still be a viable option, due to both the longer time for trehalose production and the decrease in macromolecular crowing after longer duration of hyperosmosis (Liu et al. 2019).

\section{Clade I present in both freshwater-adapted and seawater-adapted $\mathrm{Ca}$. Accumulibacter phosphatis sludge}

Ca. Accumulibacter phosphatis clade I was the dominant clade in cultures that were adapted to freshwater and cultures that were adapted to $30 \%$ seawater (Fig. 2). This flexibility of a single organism to thrive in different levels of salinity is remarkable, especially compared to other commonly studied bacteria in wastewater treatment such as nitrifying bacteria and Anammox bacteria (Moussa et al. 2006; Kartal et al. 2006; Bassin et al. 2011; Borin et al. 2013; Gonzalez-Silva et al. 2016).
The adaptability of $\mathrm{Ca}$. Accumulibacter phosphatis to a range of salinities is in line with the estuarine environments in which they were found in nature. This habitat is prone to cyclical variations in salinity, aerobicity, and nutrient availability, due to tidal fluctuations and mixing of seawater and freshwater (Pritchard 1952; Boynton and Kemp 1985). Ca. Accumulibacter has been found in the sediment-water interface of these dynamic environments (Davelaar 1993; Hupfer et al. 2007; Watson et al. 2019). Interestingly, clade I has been observed more frequently than clade II (Peterson et al. 2008). The newfound presence of trehalose as an osmolyte can add to the understanding of the adaptation strategy of $C a$. Accumulibacter to these environments.

Acknowledgments This research is financed by the Netherlands Organization for Scientific Research (NWO), which is partly funded by the Ministry of Economic Affairs and co-financed by the Netherlands Ministry of Infrastructure and Environment and partners of the Dutch Water Nexus consortium (project nr. STW 14300 Water Nexus 2.1). We would like to thank Ben Abbas for his help with next-generation sequencing, Leonor Guedes da Silva for her help with reactor work, Cor Ras for his help with trehalose measurements, and Nick Ivens for his help with osmolyte analysis and genome analysis.

Author contribution DG, ML, and MP conceived and designed the experiments. DG conducted the lab work. ML and MP gave advice on the results and further experimental design. DG wrote the manuscript. All authors read and approved the manuscript.

Funding This research is financed by the Netherlands Organisation for Scientific Research (NWO), which is partly funded by the Ministry of Economic Affairs and Climate Policy, and co-financed by the Netherlands Ministry of Infrastructure and Water Management and partners of the Dutch Water Nexus consortium.

Data availability Data is available upon request.

\section{Compliance with ethical standards}

Conflict of interest The authors declare that they have no conflict of interest.

Ethics approval Not applicable.

Consent to participate Not applicable.

Consent for publication Not applicable.

Code availability Not applicable.

Open Access This article is licensed under a Creative Commons Attribution 4.0 International License, which permits use, sharing, adaptation, distribution and reproduction in any medium or format, as long as you give appropriate credit to the original author(s) and the source, provide a link to the Creative Commons licence, and indicate if changes were made. The images or other third party material in this article are included in the article's Creative Commons licence, unless indicated otherwise in a credit line to the material. If material is not included in the article's Creative Commons licence and your intended use is not permitted by statutory regulation or exceeds the permitted use, you will 
need to obtain permission directly from the copyright holder. To view a copy of this licence, visit http://creativecommons.org/licenses/by/4.0/.

\section{References}

Altschul S, Madden TL, Schäffer AA, Zhang J, Zhang Z, Miller W, Lipman DJ (1997) Gapped BLAST and PSI-BLAST: a new generation of protein database search programs. Nucleic Acids Res 25: 3389-3402. https://doi.org/10.1093/nar/25.17.3389

Amann RI, Binder BJ, Olson RJ, Chisholm SW, Devereux R, Stahl DA (1990) Combination of 16S rRNA-targeted oligonucleotide probes with flow cytometry for analyzing mixed microbial populations. Appl Environ Microbiol 56:1919-1925

Bassin JP, Pronk M, Muyzer G, Kleerebezem R, Dezotti M, van Loosdrecht MCM (2011) Effect of elevated salt concentrations on the aerobic granular sludge process: linking microbial activity with microbial community structure. Appl Environ Microbiol 77:79427953. https://doi.org/10.1128/AEM.05016-11

Bishop SH, Greenwalt DE, Kapper MA, Paynter KT, Ellis LL (1994) Metabolic regulation of proline, glycine, and alanine accumulation as intracellular osmolytes in ribbed mussel gill tissue. J Exp Zool 268:151-161. https://doi.org/10.1002/jez.1402680213

Blackall LL, Crocetti GR, Saunders AM, Bond PL (2002) A review and update of the microbiology of enhanced biological phosphorus removal in wastewater treatment plants. Antonie Van Leeuwenhoek 81:681-691. https://doi.org/10.1023/A:1020538429009

Boos W, Ehmann U, Forkl H, Klein W, Rimmele M, Postma P (1990) Trehalose transport and metabolism in Escherichia coli. J Bacteriol 172:3450-3461. https://doi.org/10.1128/jb.172.6.3450-3461.1990

Borin S, Mapelli F, Rolli E, Song B, Tobias C, Schmid MC, De Lange GJ, Reichart GJ, Schouten S, Jetten M, Daffonchio D (2013) Anammox bacterial populations in deep marine hypersaline gradient systems. Extremophiles 17:289-299. https://doi.org/10.1007/ s00792-013-0516-x

Boynton W, Kemp W (1985) Nutrient regeneration and oxygen consumption by sediments along an estuarine salinity gradient. Mar Ecol Prog Ser 23:45-55

Chandra G, Chater KF, Bornemann S (2011) Unexpected and widespread connections between bacterial glycogen and trehalose metabolism. Microbiology 157:1565-1572. https://doi.org/10.1099/mic.0.044263-0

Comeau Y, Hall KJ, Hancock REW, Oldham WK (1986) Biochemical model for enhanced biological phosphorus removal. Water Res 20: 1511-1521. https://doi.org/10.1016/0043-1354(86)90115-6

Corsino SF, Capodici M, Morici C, Torregrossa M, Viviani G (2016) Simultaneous nitritation-denitritation for the treatment of high-strength nitrogen in hypersaline wastewater by aerobic granular sludge. Water Res 88:329-336. https://doi.org/10.1016/j.watres.2015.10.041

Crocetti GR, Hugenholtz P, Bond PL, Schuler A, Keller J, Jenkins D, Blackall LL (2000) Identification of polyphosphate-accumulating organisms and design of 16S rRNA-directed probes for their detection and quantitation. Appl Environ Microbiol 66:1175-1182. https://doi.org/10.1128/AEM.66.3.1175-1182.2000

Crocetti GR, Bond PL, Banfield JF, Blackall LL, Keller J (2002) Glycogen-accumulating organisms in laboratory-scale and fullscale wastewater treatment processes. Microbiology 148:33533364. https://doi.org/10.1099/00221287-148-11-3353

Csonka LN (1989) Physiological and genetic responses of bacteria to osmotic stress. Microbiol Rev 53:121-147

da Costa MS, Santos H, Galinski EA (1998) An overview of the role and diversity of compatible solutes in Bacteria and Archaea. Adv Biochem Eng Biotechnol 61:117-153. https://doi.org/10.1007/ $\mathrm{BFb} 0102291$
Dai X, Zhu M (2018) High Osmolarity modulates bacterial cell size through reducing initiation volume in Escherichia coli. $\mathrm{mSphere}$ 3:e00430-e00418. https://doi.org/10.1128/MSPHERE.00430-18

Daims H, Brühl A, Amann R, Schleifer K-H, Wagner M (1999) The domain-specific probe EUB338 is insufficient for the detection of all bacteria: development and evaluation of a more comprehensive probe set. Syst Appl Microbiol 22:434 444. https://doi.org/10.1016/ S0723-2020(99)80053-8

Davelaar D (1993) Ecological significance of bacterial polyphosphate metabolism in sediments. Hydrobiologia 253:179-192. https://doi. org/10.1007/BF00050737

de Graaff DR, van Loosdrecht MCM, Pronk M (2020) Biological phosphorus removal in seawater-adapted aerobic granular sludge. Water Res 172:115531. https://doi.org/10.1016/j.watres.2020.115531

Dorsaz N, De Michele C, Piazza F, De Los Rios P, Foffi G (2010) Diffusion-limited reactions in crowded environments. Phys Rev Lett 105:120601. https://doi.org/10.1103/PhysRevLett.105.120601

Elbein AD, Mitchell M (1973) Levels of glycogen and trehalose in Mycobacterium smegmatis and the purification and properties of the glycogen synthetase. J Bacteriol 113:863-873

Elbein AD, Pan YT, Pastuszak I, Carroll D (2003) New insights on trehalose: a multifunctional molecule. Glycobiology 13:17R-27R. https://doi.org/10.1093/glycob/cwg047

Ellis RJ, Minton AP (2003) Join the crowd. Nature 425:27-28. https:// doi.org/10.1038/425027a

Flowers JJ, He S, Yilmaz S, Noguera DR, McMahon KD (2009) Denitrification capabilities of two biological phosphorus removal sludges dominated by different "Candidatus Accumulibacter" clades. Environ Microbiol Rep 1(6):583-588

François J, Parrou JL (2001) Reserve carbohydrates metabolism in the yeast Saccharomyces cerevisiae. FEMS Microbiol Rev 25:125145. https://doi.org/10.1016/S0168-6445(00)00059-0

Gonzalez-Silva BM, Jonassen KR, Bakke I, Østgaard K, Vadstein O (2016) Nitrification at different salinities: biofilm community composition and physiological plasticity. Water Res 95:48-58. https:// doi.org/10.1016/J.WATRES.2016.02.050

Guedes da Silva L, Gamez KO, Gomes JC, Akkermans K, Welles L, Abbas B, van Loosdrecht MCM, Wahl SA (2018) Revealing metabolic flexibility of Candidatus Accumulibacter phosphatis through redox cofactor analysis and metabolic network modeling. bioRxiv: 458331. https://doi.org/10.1101/458331

Guillouet S, Engasser JM (1995) Sodium and proline accumulation in Corynebacterium glutamicum as a response to an osmotic saline upshock. Appl Microbiol Biotechnol 43:315-320. https://doi.org/ 10.1007/BF00172831

Guo G, Wu D, Ekema GA, Huo T, Mackey HR, Chen G (2018) Denitrifying sulfur conversion-associated EBPR: effects of temperature and carbon source on anaerobic metabolism and performance. Water Res 141:9-18. https://doi.org/10.1016/j.watres.2018.04.028

Gutierrez C, Ardourel M, Bremer E, Middendorf A, Boos W, Ehmann U (1989) Analysis and DNA sequence of the osmoregulated treA gene encoding the periplasmic trehalase of Escherichia coli K12. MGG Mol Gen Genet 217:347-354. https://doi.org/10.1007/BF02464903

Hupfer M, Gloess S, Grossart H (2007) Polyphosphate-accumulating microorganisms in aquatic sediments. Aquat Microb Ecol 47:299 311. https://doi.org/10.3354/ame047299

Kartal B, Koleva M, Arsov R, van der Star W, Jetten MSM, Strous M (2006) Adaptation of a freshwater anammox population to high salinity wastewater. J Biotechnol 126:546-553. https://doi.org/10. 1016/J.JBIOTEC.2006.05.012

Kempf B, Bremer E (1998) Uptake and synthesis of compatible solutes as microbial stress responses to high-osmolality environments. Arch Microbiol 170:319-330. https://doi.org/10.1007/s002030050649

Kim K-S, You J, Kim S, Lee H, Ahn K-H, Kim I (2007) Relationship between the electric conductivity and phosphorus concentration 
variations in an enhanced biological nutrient removal process. Water Sci Technol 55(1-2):203-208. https://doi.org/10.2166/wst.2007.053

Klipp E, Nordlander B, Krüger R, Gennemark P, Hohmann S (2005) Integrative model of the response of yeast to osmotic shock. Nat Biotechnol 23:975-982. https://doi.org/10.1038/nbt1114

Lang F, Busch GL, Ritter M, Völk1 H, Waldegger S, Gulbins E, Häussinger D (1998) Functional significance of cell volume regulatory mechanisms. Physiol Rev 78:247-306. https://doi.org/10.1152/ physrev.1998.78.1.247

Liu B, Hasrat Z, Poolman B, Boersma AJ (2019) Decreased effective macromolecular crowding in Escherichia coli adapted to hyperosmotic stress. J Bacteriol 201:e00708-e00718. https://doi. org/10.1128/JB.00708-18

Maruta K, Mitsuzumi H, Nakada T, Kubota M, Chaen H, Fukuda S, Sugimoto T, Kurimoto M (1996) Cloning and sequencing of a cluster of genes encoding novel enzymes of trehalose biosynthesis from thermophilic archaebacterium Sulfolobus acidocaldarius. Biochim Biophys Acta, Gen Subj 1291:177-181. https://doi.org/10.1016/S0304-4165(96)00082-7

Miermont A, Waharte F, Hu S, McClean MN, Bottani S, Léon S, Hersen P (2013) Severe osmotic compression triggers a slowdown of intracellular signaling, which can be explained by molecular crowding. Proc Natl Acad Sci U S A 110:5725-5730. https://doi.org/10.1073/pnas. 1215367110

Morbach S, Krämer R (2003) Impact of transport processes in the osmotic response of Corynebacterium glutamicum. J Biotechnol 104:69-75. https://doi.org/10.1016/S0168-1656(03)00164-0

Moussa MS, Sumanasekera DU, Ibrahim SH, Lubberding HJ, Hooijmans CM, Gijzen HJ, van Loosdrecht MCM (2006) Long term effects of salt on activity, population structure and floc characteristics in enriched bacterial cultures of nitrifiers. Water Res 40:1377-1388. https://doi.org/10.1016/J.WATRES.2006.01.029

Pade N, Hagemann M, Pade N, Hagemann M (2014) Salt acclimation of cyanobacteria and their application in biotechnology. Life 5:25-49. https://doi.org/10.3390/life5010025

Peterson SB, Warnecke F, Madejska J, McMahon KD, Hugenholtz P (2008) Environmental distribution and population biology of Candidatus Accumulibacter, a primary agent of biological phosphorus removal. Environ Microbiol 10:2692-2703. https://doi.org/10. 1111/j.1462-2920.2008.01690.x

Pritchard D (1952) Salinity distribution and circulation in the Chesapeake Bay estuarine system. J Mar Res 11:106-123

Roberts MF (2005) Organic compatible solutes of halotolerant and halophilic microorganisms. Saline Syst 1:5. https://doi.org/10.1186/ 1746-1448-1-5

Roeßler M, Müller V (2001) Osmoadaptation in bacteria and archaea: common principles and differences. Environ Microbiol 3:743-754. https://doi.org/10.1046/j.1462-2920.2001.00252.x

Ruhal R, Kataria R, Choudhury B (2013) Trends in bacterial trehalose metabolism and significant nodes of metabolic pathway in the direction of trehalose accumulation. Microb Biotechnol 6:493-502. https://doi.org/10.1111/1751-7915.12029

Sauer T, Galinski EA (1998) Bacterial milking: a novel bioprocess for production of compatible solutes. Biotechnol Bioeng 57:306-313. https://doi.org/10.1002/(SICI)1097-0290(19980205)57:3<306:: AID-BIT7>3.0.CO;2-L

Schäffer AA, Aravind L, Madden TL, Shavirin S, Spouge JL, Wolf YI, Koonin EV, Altschul SF (2001) Improving the accuracy of PSIBLAST protein database searches with composition-based statistics and other refinements. Nucleic Acids Res 29:2994-3005. https:// doi.org/10.1093/nar/29.14.2994

Seibold GM, Eikmanns BJ (2007) The glgX gene product of Corynebacterium glutamicum is required for glycogen degradation and for fast adaptation to hyperosmotic stress. Microbiology 153: 2212-2220. https://doi.org/10.1099/mic.0.2006/005181-0
Seviour RJ, Mino T, Onuki M (2003) The microbiology of biological phosphorus removal in activated sludge systems. FEMS Microbiol Rev 27:99-127. https://doi.org/10.1016/S0168-6445(03)00021-4

Singh M, Srivastava RK (2011) Sequencing batch reactor technology for biological wastewater treatment: a review. Asia-Pacific J Chem Eng 6:3-13. https://doi.org/10.1002/apj.490

Skjerdal OT, Sletta H, Flenstad SG, Josefsen KD, Levine DW, Ellingsen TE (1996) Changes in intracellular composition in response to hyperosmotic stress of $\mathrm{NaCl}$, sucrose or glutamic acid in Brevibacterium lactofermentum and Corynebacterium glutamicum. Appl Microbiol Biotechnol 44:635-642. https://doi.org/10.1007/ BF00172497

Sleator RD, Hill C (2001) Bacterial osmoadaptation: the role of osmolytes in bacterial stress and virulence. FEMS Microbiol Rev 26:49-71. https://doi.org/10.1111/j.1574-6976.2002.tb00598.x

Smolders GJF, van der Meij J, van Loosdrecht MCM, Heijnen JJ (1994) Model of the anaerobic metabolism of the biological phosphorus removal process: stoichiometry and $\mathrm{pH}$ influence. Biotechnol Bioeng 43:461-470. https://doi.org/10.1002/bit.260430605

Stokholm-Bjerregaard M, McIlroy SJ, Nierychlo M, Karst SM, Albertsen M, Nielsen PH (2017) A critical assessment of the microorganisms proposed to be important to enhanced biological phosphorus removal in full-scale wastewater treatment systems. Front Microbiol 8: 718. https://doi.org/10.3389/fmicb.2017.00718

Sudmalis D, Millah SK, Gagliano MC, Butré CI, Plugge CM, Rijnaarts HHM, Zeeman G, Temmink H (2018) The potential of osmolytes and their precursors to alleviate osmotic stress of anaerobic granular sludge. Water Res 147:142-151. https://doi.org/10.1016/J. WATRES.2018.09.059

Vishniac W, Santer M (1957) The Thiobacilli. Microbiol Mol Biol Rev 21:195-213

Vyrides I, Stuckey DC (2017) Compatible solute addition to biological systems treating waste/wastewater to counteract osmotic and other environmental stresses: a review. Crit Rev Biotechnol 37:865-879. https://doi.org/10.1080/07388551.2016.1266460

Wang J, Lu H, Chen G-H, Lau GN, Tsang WL, van Loosdrecht MCM (2009) A novel sulfate reduction, autotrophic denitrification, nitrification integrated (SANI) process for saline wastewater treatment. Water Res 43:2363-2372. https://doi.org/10.1016/J.WATRES.2009.02.037

Wang Z, van Loosdrecht MCM, Saikaly PE (2017) Gradual adaptation to salt and dissolved oxygen: strategies to minimize adverse effect of salinity on aerobic granular sludge. Water Res 124:702-712. https:// doi.org/10.1016/J.WATRES.2017.08.026

Watson SJ, Needoba JA, Peterson TD (2019) Widespread detection of Candidatus Accumulibacter phosphatis, a polyphosphateaccumulating organism, in sediments of the Columbia River estuary. Environ Microbiol 21:1369-1382. https://doi.org/10.1111/14622920.14576

Welles L, Lopez-Vazquez CM, Hooijmans CM, van Loosdrecht MCM, Brdjanovic D (2014) Impact of salinity on the anaerobic metabolism of phosphate-accumulating organisms (PAO) and glycogenaccumulating organisms (GAO). Appl Microbiol Biotechnol 98: 7609-7622. https://doi.org/10.1007/s00253-014-5778-4

Yancey PH, Clark ME, Hand SC, Bowlus RD, Somero GN (1982) Living with water stress: evolution of osmolyte systems. Science 217: 1214-1222. https://doi.org/10.1126/science.7112124

Zimmerman SB, Minton AP (1993) Macromolecular crowding: biochemical, biophysical, and physiological consequences. Annu Rev Biophys Biomol Struct 22:27-65. https://doi.org/10.1146/annurev. bb.22.060193.000331

Publisher's note Springer Nature remains neutral with regard to jurisdictional claims in published maps and institutional affiliations. 